\title{
Response in Cadmium Tolerance of Penicillium cyclopium Westling Subsequent to Exposure to Gamma Irradiation
}

\author{
Dipanwita Das $^{1,3,4}$, Debargha Chakraborty ${ }^{2,4}$ Anindita Chakraborty $^{3}$, Subhas Chandra Santra ${ }^{4}$ \\ ${ }^{1}$ Amity University, Kolkata Campus, Rajarhat, Newtown, Kolkata, West Bengal 700156, India \\ ${ }^{2}$ Candor International School, Bengaluru 560105, India \\ ${ }^{3}$ UGC-DAE, Consortium for Scientific Research, 3/LB-8,Saltlake, Kolkata 700098, India \\ ${ }^{4}$ Department of Environmental Science, University of Kalyani, Kalyani, Nadia 741235, West Bengal, India
}

${ }^{*}$ Correspondence E-mail : ddas@kol.amity.edu

\begin{abstract}
Role of gamma irradiation in modulating 1.1 times more cadmium (Cd) tolerance in Penicillium cyclopium Westling has been detailed in this paper. Augmentation in metal tolerance was recognized by escalation in response to Cadmium and Cd removal efficacies than that of their un-irradiated group. FTIR spectra and electron microscopic photographs further strengthen the role of low absorbed dose of gamma in modulating $\mathrm{Cd}$ tolerance in P.cyclopium. Up regulated activities of antioxidatives in gamma exposed fungal groups might be the reason for enhanced Cd tolerance than that of their un-irradiated counter parts. This findings reveal a positive and eco-friendly step for heavy metal bioremediation and metal stressed lignocellulosic waste degradation.
\end{abstract}

Keywords: P. cyclopium; Gamma Bioremediation; Antioxidative defense system

\section{Introduction}

Cadmium is a non-essential element that negatively affect ecosystem. Due to its high mobility Cadmium affect plant health at very low concentration (Barceló and Poschenrieder, 1990). Due to cost and inadequate efficiencies of conventional heavy metal removal methods, an alternative for metal elimination was a prolonged research for the scientists. Recently microbial bioremediation is considered as a sustainable and ecofriendly tool to clear-out polluted situation (Tarekegen et al., 2020) Having higher surface to volume ratio fungi are considered better prospective to be used in bioremediation than the other microbes and in turn fungi utilize the metal for its normal growth and metabolism (Abioye et al.,2018).

Current biotechnological research such as using physical and chemical mutagens significantly modified microbial output in different industrial and environmental field. Gamma being such a physical mutagen established its potential for microbial strain improvement (Dadachova et al., 2007; Robertson et al., 2012) although higher doses of gamma used as an excellent tool for sterilization, food preservation and different food engineering process (Singh et al., 2016). Enhanced industrial enzyme activities in gamma exposed fungal strains than that of their un-irradiated counterparts were also reported by Iftikhar et al. (2010), Huma et al. (2012) and Aleem et al.(2018).

In this perspective this work is stipulated to appraise the role of gamma irradiation on $\mathrm{Cd}$ tolerance, change in metabolic enzyme activities in Penicillium cyclopium and simultaneously the depiction of anti-oxidative 
activities in gamma exposed $P$. cyclopium grown in $\mathrm{Cd}$ riched growth media.

\section{Materials and Methods}

\section{Gamma exposure to the spore suspension}

According to the method of Kava-Cordeiro et al.(1995) spore suspension of Penicillium cyclopium Westling (2ml suspension containing $5 \times 10^{5}$ spores $/ \mathrm{ml}$ )was prepared using Tween20 $(0.02 \% \mathrm{v} / \mathrm{v})$ and $\mathrm{NaCl}$ $(0.85 \% \mathrm{w} / \mathrm{v})$ solution and were exposed to 20 100 Gray of absorbed doses of gamma (absorbed dose of gamma calculated by Fricke Dosimetry) from a $\mathrm{Co}^{60}$ gamma source (GC 1200, BRIT). The fungal strain isolated from soil of garbage dump site of Dhapa, Kolkata identified following standard fungal identification key (Frisvad and Filtenborg 1989). All further experiments were done considering MIC (Minimum Inhibitory Concentration) and in close proximity to MIC.

\section{Estimation of Colony Forming Unit (CFU) andand Cd removal efficacy}

How significantly cadmium removed (from the liquid growth media) by gamma exposed fungal groups compared to their unirradiated counterparts were evaluated following the method of Srivastava and Thakur (2006) in AAS (Atomic Absorption Spectrophotometer; FI-HG-AAS Perkin Elmer Analyst 400).

Analysis of the functional groups involved in Cd adsorption

The efficient functional groups (present in fungal cell wall) responsible in metal adsorption were studied through FTIR (JASCO-6300 FTIR with a diffuse reflectance mode (DRS8000) attachment) following the methods of Xu et al. (2009).

\section{Analysis of Morphological structures}

Fungal samples(prepared according to the methods of Mishra and Malik (2013)were gold coated in $\mathrm{IB}_{2} \mathrm{ION}$ Coater for $30 \mathrm{mins}$ and observed in SEM (HITACHI S-530),keeping the constant voltageat $25 \mathrm{KeV}$.

\section{Antioxidant activity}

Super-oxide dismutase (SOD), Catalase (CAT), total Glutathione (GSH) level and antioxidant Metallothionein (MT) were studied as antioxidative response.SOD activity was measured following the method of Paoletti et al., (1990). CAT activity was measured following the method of Aebi (1984).Total reduced glutathione was assayed according to the method of Moron et al., (1979).Quantitative estimation of metallothionein protein was estimated according to the method of Viarengo et al.(1997) and modified according to the method of Pal et al. (2005).

\section{Results}

Current study establishes the potential of low absorbed doses of gamma in amending metal tolerance in fungi. Low doses of ionizing radiation could improve cadmium tolerance in $P$. cyclopium which is inferred through the significant escalation of number of CFUs, metal removal efficacies.

\section{Acceleration in Cd tolerance and removal efficacies}

Gamma irradiated P. cyclopium showed 1.1 times more $\mathrm{Cd}$ tolerance in terms of CFU (colony forming unit) and higher removal potential than that of their un-irradiated counterparts. Gamma exposed P. cyclopium could grow in 750ppm of $\mathrm{Cd}$ in growth media while the un-irradiated group could tolerate upto 650ppm.Prior exposed to gamma (20Gy$100 \mathrm{~Gy}$ )and then grown in 300-650 ppm of $\mathrm{Cd}, P$. cyclopium showed a radiation dose dependent enhancement of CFU up to a certain dose of gamma exposure. Effective dose showing maximum escalation in CFU was noticed at $80 \mathrm{~Gy}$ against $300 \mathrm{ppm}$ of $\mathrm{Cd}$ and against $650 \mathrm{ppm}$ that effective dose was at 60Gy. 20-60Gy irradiated P.cyclopium grown in 300ppm of $\mathrm{Cd}$ showed $20 \%-73 \%$ increase in CFU (Fig 1a) while at 80 Gy 1.13 fold CFU was studied than that of their un-irradiated counterparts. A slight decrease in CFU was perceived in the group exposed to 100Gy in comparison with the group exposed to 80Gy, although it was still 93\% more than unirradiated counterparts. Further increase in metal concentration i.e against at $650 \mathrm{ppm}$ the effective dose manifesting maximum (1.2fold) CFU was noted at 60Gy (Fig 1a). In contrast to no growth of P.cyclopium at only $750 \mathrm{ppm} \mathrm{Cd}$, gamma exposed group showed significant growth of the fungi having maximum CFU in the group exposed at 40Gy (absorbed dose) of 
gamma irradiation (Fig 1b). CFU analysis depicted an interesting data which corroborated the potential of gamma irradiation in augmenting $\mathrm{Cd}$ tolerance of P.cyclopium

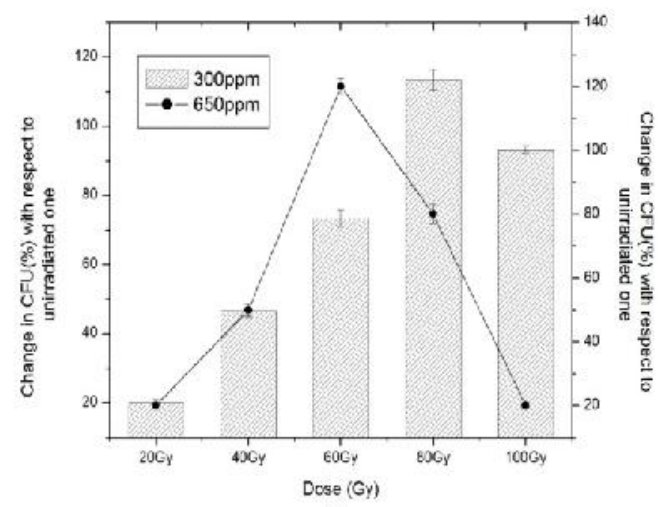

(a)

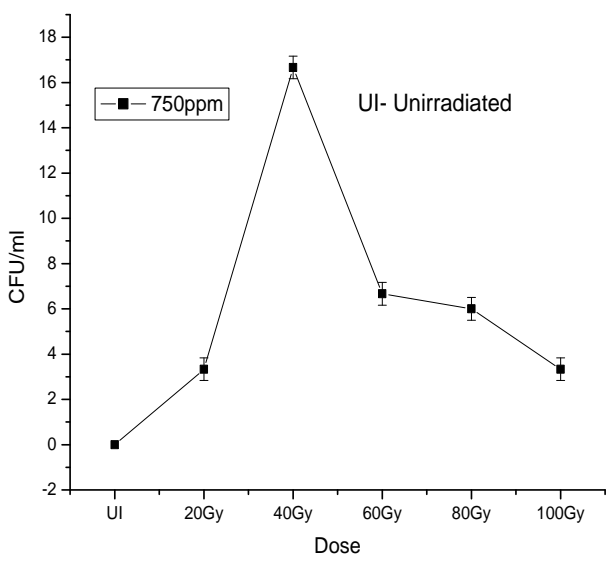

(b)

Fig.1 Colony Forming Unit of $P$. cyclopium with or without exposure to gamma irradiation grown in Cd riched media (a) 300ppm 650ppm Cd (b) 750ppm Cd(n=6. p $\leq 0.05$ was considered significant)

Data of AAS analysis reveal significant $(p \leq 0.05)$ potential of gamma irradiation in amending $\mathrm{Cd}$ removal by $P$. cyclopium. 80Gy and 60Gy (effective dose showing maximum CFU against 300ppm and 650ppm respectively) exposed $P$. cyclopium when grown in 300ppm and 650ppm of cadmium respectively could remove $13 \%$ more cadmium than its un-irradiated counterparts. Interestingly 40Gy exposed $P$. cyclopium could remove $60 \%$ of $\mathrm{Cd}$ from when grown in 750ppm Cd, while un-irradiated one could not grow in such higher concentrations of $\mathrm{Cd}$ (Fig2). Inherent properties of microbes in interaction of metals have been reported by a host of researchers (Igiri et al., 2018). In this study gamma induced escalation of $\mathrm{Cd}$ removal potential of irradiated fungal strains imitate the role of gamma in response of fungi towards heavy metals. Improvement in metal resistance. Impact of low doses of gamma irradiation on fungi have been reported earlier by Abbasi et al.(2016); de Queiroz Baptista et al.,(2015); Dadachova et al.(2007). Actually genetic manipulation of fungi is done to improve some specific factor and gamma has the potential to cause mutation to the genes of cells through DNA repair mechanism (Huma et al., 2012). In this study difference in gene expression due to exposure to gamma irradiation might be the cause behind higher Cd tolerance and removal by radiation exposed P.cyclopium. Such exposures may also enhance immune reactions of the organism and attenuate harmful effects of higher doses of radiation.



Fig. 2 Removal of $\mathrm{Cd}$ by $P$. cyclopium (with and without exposure to gamma irradiation) ( $\mathrm{n}$ $=6 . p \leq 0.05$ was considered significant)

\section{Depiction of FTIR spectrum and SEM image}

Fig3 shows the FTIR spectra of different groups of $P$. cyclopium biomass. Spectral data analysis showed involvement of different functional groups (amide group [-NH], hydroxyl group $[-\mathrm{OH}]$, carboxylate group [-COO], carbonyl group [-CO]) in $\mathrm{Cd}$ adsorption. Significant shift in peak regions were found at $3394 \mathrm{Cm}^{-1}, 2928 \mathrm{Cm}^{-1}, 1548 \mathrm{Cm}^{-1}, 1240 \mathrm{Cm}^{-1}$ regions both in gamma exposed and unexposed biomass of P.cyclopium grown in Cd supplemented media with respect to its 
control (Cd free biomass). The peak at 3394 $\mathrm{Cm}^{-1}$ region observed in the control P.cyclopium biomass (Fig 3a) was noted to be shifted to $3363 \mathrm{Cm}^{-1}$ in $\mathrm{Cd}$ exposed biomass (Fig-3b) while in gamma irradiated and $\mathrm{Cd}$ treated group the same peak was shifted to $3385 \mathrm{Cm}^{-1}$ (Fig 3c).

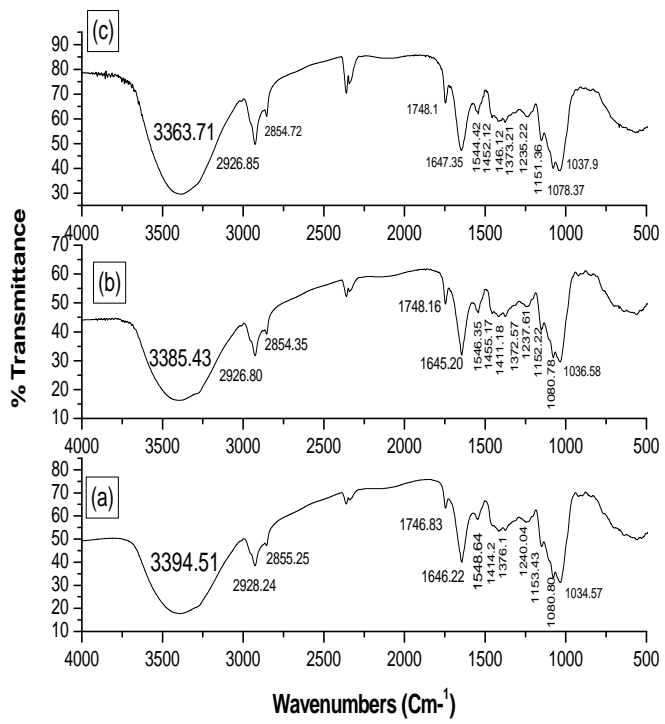

Fig. 3 FTIR spectrum showing effective functional groups (present in cell wall) responsible for $\mathrm{Cd}$ adsorption of P.cyclopium biomass

(a) Control biomass; (b) 300ppm Cd riched biomass (c) 80Gy gamma exposed biomass grown in 300ppm Cd riched media

Peaks in the regions $1548 \mathrm{Cm}^{-1}$ and $1240 \mathrm{Cm}^{-1}$ were also noted to be shifted in the two experimental groups as compared to the normal control group. One new peak at 1450 $\mathrm{Cm}^{-1}$ region was noted in $\mathrm{Cd}$ treated biomass with or without gamma exposure, which was not observed in control one. Significant changes in the same functional groups in the gamma exposed fungi additionally treated with metals, confirms potential of gamma irradiation in modulating heavy metal tolerance in fungi involving important functional groups. Similar type of results have been reported earlier also (Manal et al., 2020; Rudakiya et al., 2018).

Cylindrical normal hyphae distorted into thinner with flocculations and pores after exposed to metal stress (Fig. 4a \& 4b). However, prior exposed to gamma and then grown in metal enriched growth media, the fungal hyphae exhibited less structural deformities (Fig. 4c). Manal et al., (2020) also noticed alteration of normal structure of the fungal hyphae exposed to the heavy metals. Upholding close to normal hyphal morphology in gamma exposed groups indicate potential of gamma in providing protection against metalinduced morphological alteration.
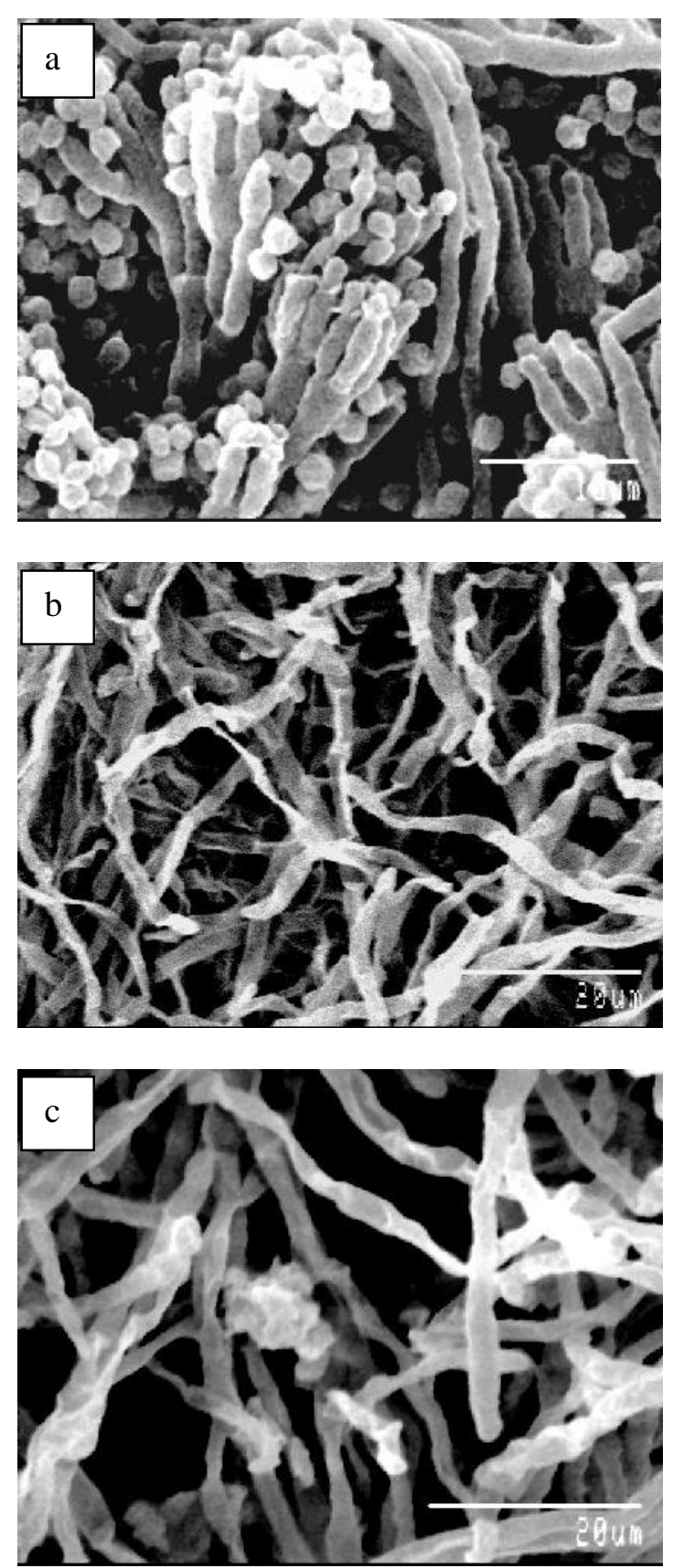

Fig. 4 Hyphal morphology (SEM) of P.cyclopium (1500-2000X)[a : Control P.cyclopium, b : 300ppm Cd treated 
P.cyclopium, c: 80Gy exposed P.cyclopium grown in 300ppm Cd]

\section{Change in Antioxidative activities}

Any chemical or physiological stress (metal and gamma exposure) produce Reactive Oxygen Species (ROS) such as superoxide anion radical $\left(\mathrm{O}_{2}{ }^{-}\right)$, hydrogen peroxide, and hydroxyl radical $(\mathrm{OH})$ (Fridovich, 1995) which cause harm for the cell damaging DNA, lipids and proteins. To combat the stress of ROS all living cells upregulate their non-enzymatic and enzymatic antioxidant defense mechanisms. In this study the escalation of anti-oxidative response in metal treated fungal strains proved their role in protecting fungi from the toxicity of heavy metals (Fig.5a). Further increase in antioxidant activities in gamma exposed group of fungi (grown in metal treated growth media) suggest potential of low doses of gamma in better tolerance of heavy metals in fungi (Fig. $5 \mathrm{~b} \& 5 \mathrm{c}$ ).300ppm of $\mathrm{Cd}$ in growth media of P.cyclopium resulted in two times increase in SOD and CAT activity and 1.8times more GSH level as compared to control group of the fungi without having any metal treatment. A higher concentration of $\mathrm{Cd}$ in growth media (650ppm) manifested further increase in all the three parameters.80Gy exposed P.cyclopium grown in 300ppm Cd supplemented growth media manifested 2fold increase in activity of both SOD and CAT and 1.6 times GSH level (Fig5b). 60Gy exposed P.cyclopium grown in 650ppm of $\mathrm{Cd}$ showed higher stimulation in activities of these markers as compared to that of its un-irradiated counterparts when grown under same metal stress. Upregulation of antioxidative enzymes and anti-oxidants after being treated with heavy metals in fungal strains were reported by a group of researchers (Huang et. al., 2017; Krumova et al., 2011). Similar result was also noticed by Robertson et al. (2012) in W. dermatitidis cells exposed to radiation. In short, this validates ionizing radiation activates DNA repair mechanism and anti-oxidative defense systems as mentioned by Huma et al., (2012). MTs have been shown to be associated in intracellular sequestrations of heavy metals and balancing oxidative stress along with other numerous cellular functions.
This study portrays $48 \%$ more MT in P.cyclopium when grown in Cd supplemented media (300ppm) while prior exposed to $80 \mathrm{~Gy}$ and then grown in same $\mathrm{Cd}$ enriched media (300ppm) showed 23\% more MT content when compared to their un-irradiated but $\mathrm{Cd}$ stressed counterparts (Table 1 ).
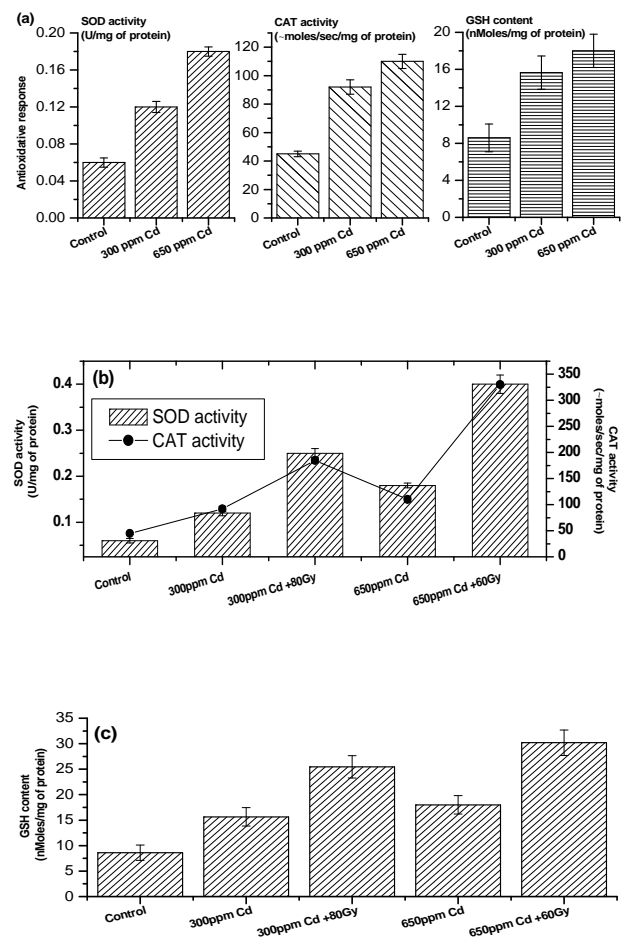

Fig. 5 Antioxidative response of Penicillium cyclopium ( $\mathrm{n}=6 . \mathrm{p} \leq 0.05$ was considered significant.)

\begin{tabular}{|c|c|}
\hline Sample & $\begin{array}{c}\text { Total } \\
\text { Metallothionein } \\
(\mu \mathrm{mole} / \mathrm{mg} \text { of } \\
\text { protein) }\end{array}$ \\
\hline Control P. cyclopium & $10.35 \times 10^{-5}$ \\
\hline $\begin{array}{c}\text { 300ppm Cd exposed } \\
\text { P.cyclopium }\end{array}$ & $15.36 \times 10^{-5}$ \\
\hline $\begin{array}{c}\text { 80Gy exposed } \\
\text { P.cyclopium grown in } \\
\text { 300ppmCd }\end{array}$ & $18.85 \times 10^{-5}$ \\
\hline 80Gy exposed & $13.65 \times 10^{-5}$ \\
P.cyclopium & \\
\hline
\end{tabular}

Table 1. Metallothionein ( $\mu \mathrm{mole} / \mathrm{mg}$ of protein) in P.cyclopium

Lorenzo-Gutiérrez et al., (2019) reported same type of response in Fusarium oxysporum when exposed to heavy metals like $\mathrm{Cd}, \mathrm{Zn}$. Expression of metallothionein in gamma 
exposed fungi has not reported till now although gamma radiation induced expression of metallothionein in Plantago ovate for sk was reported by Saha et al., (2013). Data of correlation study shows positive correlation between antioxidative enzymes and marker proteins (Table 2).

\begin{tabular}{|lllll|}
\hline & SOD & CAT & GSH & MT \\
\hline SOD & & & & \\
\hline CAT & $0.88^{* *}$ & & & \\
\hline GSH & $0.91^{*}$ & $0.89^{* *}$ & & \\
\hline MT & $0.95^{\star}$ & $0.85^{* *}$ & $0.81^{* *}$ & \\
\hline Table & 2 & Values of & Correlation & matrix \\
\hline
\end{tabular}

(Pearson) between SOD, CAT, GSH, and MT of Penicillium cyclopium Westling exposed to absorbed doses of gamma (20-100 Gy) and grown in Cd-enriched growth media (Correlations were significant at ${ }^{*} \mathrm{P}<0.0001$; ** $P<0.001$ )

Precisely the recent work reveals the role of low doses of gamma radiation in augmenting cadmium tolerance in $P$. cyclopium and upregulation of antioxidative defense system might be the responsible factors for being more metal tolerant after being exposed to gamma. The higher efficiency of the radiation exposed fungi to remove heavy metals from the media highlights the possibility of utilizing low absorbed doses of ionising radiation to References

Abbasi, S., Safaie, N., Shams-Bakhsh, M., \& Shahbazi, S. (2016). Biocontrol activities of gamma induced mutants of Trichoderma harzianum against some soilborne fungal pathogens and their DNA fingerprinting. Iranian Journal of Biotechnology, 14(4), 260.

Abioye, O. P., Oyewole, O. A., Oyeleke, S. B., Adeyemi, M. O., \& Orukotan, A. A. (2018). Biosorption of lead, chromium and cadmium in tannery effluent using indigenous microorganisms. Brazilian Journal of Biological Sciences, 5(9), 25-32.

Aebi, H. (1984). [13] Catalase in vitro. Methods in Enzymology, 105, 121-126. https://doi.org/10.1016/S0076-6879(84)05016-3

Alariqi, S. A., Kumar, A. P., Rao, B. S. M., \& Singh, R. P. (2006). Biodegradation of $Y$-sterilised biomedical polyolefins under composting and fungal culture environments. Polymer Degradation and Stability, 91(5), 1105-1116. improve the bioremediation potential of the fungi.

\section{Conclusion}

Potential of gamma irradiation for enhancing Cd removal of P.cyclopium than both of their un-irradiated counterparts were evaluated in this study. Up-regulated activities of antioxidants and metabolic enzymes activities supported them to improve cadmium removal efficacies than that of their un-irradiated counterparts.

\section{Acknowledgments}

The authors are very much thankful to the UGC-DAE-CSR (UGC-DAE Consortium for Scientific Research), Kolkata Centre, for providing laboratory facilities and financial support; Department of Environmental Science, Kalyani University, India for providing AAS facility; Govt. College of Engineering and Leather Technology, Kolkata (GCELT),India, for providing Spectrophotometer; USIC, Burdwan University, for providing SEM, CRNN, Calcutta University for providing FTIR.

\section{Conflicts of Interest}

The authors declare that there are no conflicts of interest.

Aleem, B., Rashid, M. H., Zeb, N., Saqib, A., Ihsan, A., lqbal, M., \& Ali, H. (2018). Random mutagenesis of super Koji (Aspergillus oryzae): improvement in production and thermal stability of $\alpha$-amylases for maltose syrup production. BMC Microbiology, 18(1), 1-13.

Barceló, J. U. A. N., \& Poschenrieder, C. (1990). Plant water relations as affected by heavy metal stress: a review. Journal of plant nutrition, 13(1), 137.

Dadachova, E., Bryan, R. A., Huang, X., Moadel, T., Schweitzer, A. D., Aisen, P., ... \& Casadevall, A. (2007). Ionizing radiation changes the electronic properties of melanin and enhances the growth of melanized fungi. PloS one, 2(5), e457.

de Queiroz Baptista, N. M., Solidônio, E. G., de Arruda, F. V. F., de Melo, E. J. V., de Azevedo Callou, M. J., de Miranda, R., ... \& de Gusmão, N. B. (2015). Effects of gamma radiation on enzymatic production of lignolytic complex by filamentous 
fungi. African Journal of Biotechnology, 14(7), 612621.

Fridovich, I. (1989). Superoxide dismutases: an adaptation to a paramagnetic gas. Journal of Biological Chemistry, 264(14), 7761-7764.

Frisvad, J. C., \& Filtenborg, O. (1989). Terverticillate penicillia: chemotaxonomy and mycotoxin production. Mycologia, 81(6), 837-861.

Geweely, N. S., \& Nawar, L. S. (2006). Sensitivity to gamma irradiation of post-harvest pathogens of pear. Int J Agric Biol, 8(6), 710-716.

Huang, C., Lai, C., Xu, P., Zeng, G., Huang, D., Zhang, J., ... \& Wang, R. (2017). Lead-induced oxidative stress and antioxidant response provide insight into the tolerance of Phanerochaete chrysosporium to lead exposure. Chemosphere, 187, 70-77.

Huma, T., Rashid, M. H., Javed, M. R., \& Ashraf, A. (2012). Gamma ray mediated mutagenesis of Phialocephala humicola: effect on kinetics and thermodynamics of a-amylase production. African Journal of Microbiology Research, 6(22), 4639 4646.

Iftikhar T, Mubashirniaz M, Abbas QS, Zia MA, Ashraf I, Lee KJ, Haq UI (2010) Mutation induced enhanced biosynthesis of lipases by Rhizopus oligosporus var microspores. Pak. J. Bot. 42(2):1235-1249.

Igiri, B. E., Okoduwa, S. I., Idoko, G. O., Akabuogu, E. P., Adeyi, A. O., \& Ejiogu, I. K. (2018). Toxicity and bioremediation of heavy metals contaminated ecosystem from tannery wastewater: a review. Journal of toxicology, 2018:1-16.

Kava-Cordeiro, V., Luna-Alves-Lima, E. A., \& Azevedo, J. L. (1995). Survival and mutant production induced by mutagenic agents in Metarhizium anisopliae. Scientia Agricola, 52(3), 548-554.

Krumova, E., Pashova, S., Dolashka-Angelova, P., \& Angelova, M. (2011). Adaptive Response of Humicola Lutea to Copper Exposure. Biotechnology \& Biotechnological Equipment, 25(sup1), 64-71.

Lorenzo-Gutiérrez, D., Gómez-Gil, L., Guarro, J., Roncero, M. I. G., Fernández-Bravo, A., Capilla, J., \& López-Fernández, L. (2019). Role of the Fusarium oxysporum metallothionein $\mathrm{Mt} 1$ in resistance to metal toxicity and virulence. Metallomics, 11(7), 1230-1240.

Manal T. El Sayed, Ashraf S.A. El-Sayed (2020) Bioremediation and tolerance of zinc ions using Fusarium solani. Heliyon. 6 : e05048.
Mishra, A., \& Malik, A. (2012). Simultaneous bioaccumulation of multiple metals from electroplating effluent using Aspergillus lentulus. water research, 46(16), 4991-4998.

Moron MS, Depierre JW, Mannervik B (1979) Levels of glutathione, glutathione reductase and glutathione S-transferase activities in rat lungs and liver. Biochim. Biophys. Acta.582: 67-78.

Pal, S. K., \& Das, T. K. (2005). Biochemical characterization of N-methyl N'-nitro-Nnitrosoguanidine-induced cadmium resistant mutants ofAspergillus niger. Journal of biosciences, 30(5), 639-646.

Paoletti, F., \& Mocali, A. (1990). [18] Determination of superoxide dismutase activity by purely chemical system based on NAD (P) $\mathrm{H}$ oOxidation. Methods in enzymology, 186, 209-220. https://doi.org/10.1016/0076-6879(90)86110-H

Robertson, K. L., Mostaghim, A., Cuomo, C. A., Soto, C. M., Lebedev, N., Bailey, R. F., \& Wang, Z. (2012). Adaptation of the black yeast Wangiella dermatitidis to ionizing radiation: molecular and cellular mechanisms. PloS one, 7(11), e48674.

Rudakiya, D. M., lyer, V., Shah, D., Gupte, A., \& Nath, K. (2018). Biosorption potential of phanerochaete chrysosporium for arsenic, cadmium, and chromium removal from aqueous solutions. Global Challenges, 2(12), 1800064.

Singh, R., Singh, D., \& Singh, A. (2016). Radiation sterilization of tissue allografts: A review. World Journal of Radiology, 8(4), 355.

Srivastava, S., \& Thakur, I. S. (2006). Biosorption potency of Aspergillus niger for removal of chromium (VI). Current microbiology, 53(3), 232237.

Tarekegn, M. M., Salilih, F. Z., \& Ishetu, A. I. (2020). Microbes used as a tool for bioremediation of heavy metal from the environment. Cogent Food \& Agriculture, 6(1), 1783174.

Viarengo, A., Ponzano, E., Dondero, F., \& Fabbri, R. (1997). A simple spectrophotometric method for metallothionein evaluation in marine organisms: an application to Mediterranean and Antarctic molluscs. Marine Environmental Research, 44(1), 69-84.

Xu, C., Ma, F., \& Zhang, X. (2009). Lignocellulose degradation and enzyme production by Irpex lacteus CD2 during solid-state fermentation of corn stover. Journal of bioscience and bioengineering, 108(5), 372-375. 